RESEARCH ARTICLE

\title{
Analog Video in Moving Image Archives \& Conservation: Infrastructures of Knowledge from Production to Preservation
}

\author{
Lauren Sorensen \\ University of California, Los Angeles, US \\ laurensorensen@ucla.edu
}

The essay uses a set of theoretical ideas offered by Susan Leigh Star to argue for a shift in contemporary understandings of, and approaches to, video preservation. Instead of focusing on the granular characteristics of tape and their material stability, I argue, the audiovisual archival community should view preservation as a set of linked systems that function within a web of shifting perspectives and context-driven solutions.

Keywords: audiovisual archives; media conservation; analog video; infrastructure; maintenance

Study an information system and neglect its standards, wires and settings, and you miss equally essential aspects of aesthetics, justice, and change. Perhaps if we stopped thinking about computers as information highways and began to think of them more modestly as symbolic sewers, this realm would open up a bit.

- Susan Leigh Star, "Ethnography of Infrastructure" (379).

This essay is a preliminary attempt to treat a series of questions that have begun to emerge for me as I embark on a larger project that uses ethnography to consider the work of cultural heritage preservation. I use here ideas that have been developed by infrastructure studies scholars in an attempt to reconsider, and complicate, a set of prevalent narratives within the video preservation community. I do this principally through a decade-by-decade consideration of key texts produced by video preservation practitioners, funders, engineers, and advocates. I also use and reflect on excerpts from a set of preliminary, semistructured interviews that I have begun to conduct with video preservationists. Undergirding this work is my belief in the need for investigation into the knowledge and material infrastructures that have been adopted and maintained by the archival community over the past several decades in its efforts to support the work of preserving and providing access to archival video. As such, this article is a step towards a larger project in which I will conduct a broader consideration of analog video preservation infrastructure. In that larger project, I hope to document and examine the terrain of video preservation-from point of production to archive/museum context-through ethnographic interviews with moving image archivists and retired video equipment engineers, participant observation, and critical discourse analysis. I seek to understand how infrastructures of knowledge have morphed over time and space, from the analog era to the digital era and from the commercial labor sector to the cultural heritage sector. How have diverse labor practices and material conditions shaped and reshaped these ideas? In the end, this project will be about a community of practice and its members' engagement with endangered technology and the discourse that arises when that technology is itself a historical record that is quickly decaying and becoming obsolete. In this essay, however, my scope is more limited. Here I focus on tracing the key elements of video preservation discourse as they have emerged over the past few decades. My reading of this discourse leads me to suggest that archivists and preservationists would be well served by expanding their reach-by attending not only to the materiality of tape but also to processes, and by viewing video preservation through the lenses offered by Susan Leigh Star's ethnographic approach to infrastructure. 


\section{Theoretical Frameworks}

Infrastructure, Susan Leigh Star writes, is relational: 'Study an information system and neglect its standards, wires and settings, and you miss equally essential aspects of aesthetics, justice, and change' (1999: 379). To demonstrate this point, Star uses the example of city water infrastructure, which-as she describes it-is comprised of a set of relational components and gives rise to a diversity of meanings that change depending on the viewer's perspective. 'The cook considers the water system as working infrastructure integral to making dinner,' she explains, but 'for the city planner or the plumber, [the water system] is a variable in a complex planning process or a target for repair' (Star 1999: 380). As a result, she suggests, if we seek to understand the meaning and uses of a specific technology, we should consider it from a range of perspectives and resist clinging to the prettiest or simplest description. The epigraph to this essay is cited here again because of how it serves to activate the connection that the concept of infrastructure offers between scholarship and technological practice. 'Perhaps if we stopped thinking about computers,' Star writes, 'as information highways and began to think of them more modestly as symbolic sewers, this realm would open up a bit' (Star 1999: 379). Star proposes that scholars interested in these ideas use what she calls 'process-oriented documentation.' That is, they should direct our attention not simply to 'things' but relationships-or what Gregory Bateson (1978: 182) called 'an infinite regress of relationships.' 'Study[ing] the unstudied' representations of infrastructure has the power, Star (1999) suggests (quoting her teacher Anselm Straus, noted sociologist and co-author of The Discovery of Grounded Theory [1967]), to open up a more ecological understanding of workplaces, materiality, and interaction, and [underpin] a social justice agenda by valorizing previously neglected people and things' (475). As early as 1979, Straus and his students worked to study and make visible subjects like 'low-status workers such as janitors, death and dying, and the materials used in the life sciences' (Star 1999: 379), encouraging a direction in scholarship in science and technology studies that takes as its focus of interest obscure or overlooked structuring processes. Star's ideas offer an important starting point for a reconsideration of the systems and discourse-the infrastructuresurrounding the work of analog video preservation, suggesting we should foreground processes of infrastructure creation and maintenance.

In fact, elements of Star's ideas have begun to gain a foothold in the cultural heritage sector, especially among digital archivists. Borrowing from science and technology studies scholars, for instance, some archivists have begun to write about the importance of 'maintenance' and 'maintainers' in a digital era, arguing that a core element of digital preservation revolves around the work of infrastructure maintenance. Archivist Hillel Arnold (2016) notes that centering the work of 'maintainers' helps to 'correct narratives that valorize individual innovators and disruptors' and reveals the ways in which 'this emphasis on newness and innovation erases labor and bodies.' Arnold points to scholars in science and technology studies who ask "'who does maintenance work, when and where and why?"', and, in doing so, 'look to reveal and empower maintenance and the people who do it' (2016). Arnold's comments go a long way toward suggesting why viewing the discourse of video preservation through an infrastructure studies lens is valuable. It offers a way to discuss the history and possible futures of analog video preservation and conservation practice without occluding the labor, bodies, mechanical platforms, diverse perspectives, and discourse-that is, the infrastructure and process-of it.

\section{The Concerns of Materiality: Video Preservation Discourse, 1974-2002}

It is possible to trace the ways in which the core elements of video preservation discourse and infrastructure arose and developed across the past five decades by surveying the literature of video preservation as it evolved over time. From the early 1970s (when consumer video cameras were new and the issue of video preservation was first acknowledged) through the early 2000s (when practitioners began to realize that video preservation also meant digital preservation, as companies started to cease manufacture of videotape and machinery), an array of reports, books, symposia, and essays addressed and shaped professionals' understanding of the preservation needs of magnetic media and analog videotape. These writings and convenings produced a series of shifting narratives containing several constant elements-chief among which was a concern for the materiality of videotape and video playback decks.

Possibly the first major effort to address the question of video preservation was contained in a 1974 report written by Ralph Sargent and sponsored by the Corporation for Public Broadcasting and the National Endowment for the Humanities. The book, entitled Preserving the Moving Image, was mostly devoted to film preservation. But it also included a twenty-page section that featured interviews with manufacturers of videotape conducted by the Alliance of Motion Picture and Television Producers (AMPTP). These interviews offer a window onto the nascent concerns about the sustainability of magnetic media as they were arising 
among cultural heritage professionals in the early 1970s. Interviewees expressed concern about the playability of the tapes themselves, focusing attention on the magnetic signal, the physical composition of the tape base, and future improvements to lines of resolution. For instance, one $3 \mathrm{M}$ representative noted in his interview that multiple reformulations of tape had happened in manufacturing. ${ }^{1}$

These types of concerns about the materiality of video continued to dominate much of the work conducted in the 1980s. Concerned about magnetic media stability, a scholar named Edward Cuddihy conducted several scientific tests on magnetic tapes, and in the process became the first person to associate 'hydrolysis' (now sometimes called 'sticky shed syndrome') with the degradation of the material that binds iron oxide particles to the backing of a tape. He also identified 'environmental conditions of relative humidity and temperatures which are ideal for long-term archival preservation' (Cuddihy 1980: 558). NASA addressed similar questions about tape viability in a 1982 study that focused on questions of magnetic tape storage and handling (Kalil 1982). ${ }^{2}$ And when the Coordinating Council of Audiovisual Archiving Associations (CCAAA) convened a Joint Technical Symposia (JTS) in 1983, attendees discussed topics including the archiving of television and long-term storage of videotape. Participants also discussed the results of a recent survey about videotape preservation policies and practices that was focused, again, on the materiality of videotapes, as well as on the decks used to play tapes back. Of special concern to survey respondents were topics such as the wind of the videotape, the ability to play back a tape, and issues in playback such as drop-out and print-through. When the JTS met in 1987 in West Berlin, attendees discussed similar topics. Video engineers such as Gerhard Welz and Jim Wheeler described which tape formats best facilitated preservation and why consumer grade videotape decks were more likely to damage the videotape as it passed through them. These contributions are examples of the newly developing analog video preservation and maintenance community adopting the discourse of video engineering. ${ }^{3}$

The early to mid-nineties saw a surge of interest in analog video preservation, and the addition of voices from the independent media community and the newly developing field of time-based media conservation. In 1991, Downtown Community Television (DCTV) hosted a landmark symposium of video preservation. ${ }^{4}$ The content of that symposium is documented in Deirdre Boyle's Video Preservation: Securing the Future of the Past (1993), the first comprehensive, book-length consideration of the ways in which equipment obsolescence and proprietary mechanisms pose a tangible barrier to preservation. Published by the nowdefunct New York-based not-for-profit Media Alliance, Boyle's book featured materials from the symposium, results of a 1991 Media Alliance survey, a glossary, and a listing of video preservation resources (such as transfer facilities and an index of tape formats).

Concerns about sustainability of tape and playback equipment continued to garner a great deal of attention into the mid-1990s. In 1996, these concerns dominated two video preservation symposia convened by Bay Area Video Coalition (BAVC) ${ }^{5}$ and the Library of Congress. ${ }^{6}$ The Library of Congress's post-convening report covered major issues in the preservation of videotape and broadcast media, outlined potential future directions for saving media, and presented testimonies from various stakeholders in the industry, cultural heritage professions, and independent media. A 1995 report published by the Council on Library and Information Resources (CLIR) examined analog media storage and tape-to-tape copying (Van Bogart 1995).

\footnotetext{
1 This information is useful for preservationists today who are interested in the material conservation of 3M-manufactured videotape; some preservationists who operate playback decks have attempted to track tape manufacturer brand and year in order to attempt to provide a knowledge base for the more at-risk formulations. An example from the audio preservation community: http://richardhess.com/notes/formats/magnetic-media/magnetic-tapes/analog-audio/degrading-tapes/.

2 These studies are precursors of the ISO standards for the care of magnetic media that are followed by cultural heritage professionals today, but share many of the same framings and concerns (ISO 2006, 2012).

3 Jim Wheeler remained a figure in the moving image preservation field for some time, helping to develop the Association of Moving Image Archivists' (AMIA) Video Preservation Fact Sheets and other documentation coded as developing best practice. He also participated in numerous symposia on conservation of video in a museum context.

4 Downtown Community Television Center is a local New York City based media arts center, founded in 1972, alongside a number of other community organizations across the United States that were keen to make use of newly portable video technology. DCTV provides workshops and classes to this day, to promote accessibility and democracy in media creation and use. http://www.dctvny. org/.

5 Bay Area Video Coalition (BAVC) is a non-profit media arts organization based in San Francisco, California. Founded in 1976, leadership within the organization started a video preservation program in the early 1990s. https://bavc.org/preserve-media.

6 The Library of Congress recorded hearings and produced a study and report on the state of video and television preservation in the United States, which became a key document in the history of video preservation. Many different sectors of the cultural heritage community were represented, including museums, community media centers and broadcast personnel. https://www.loc.gov/ programs/national-film-preservation-board/preservation-research/television-videotape-preservation-study/.
} 
The early 2000s saw the continuation of these materiality-focused conversations. For instance, TechArcheology's 2001 symposium considered video conservation through a series of case studies, and the American Institute for Conservation of Historic and Artistic Works (AIC) devoted an entire issue of its newsletter to time-based media preservation. In 2003, the Image Permanence Institute published a three-year study that sought to 'identify the major issues in the preservation of the physical integrity of magnetic tape collections [and] ... to evaluate the possibility of developing a nondestructive diagnostic tool for assessing the condition of magnetic tape collections' (Bigourdan 2006: 1). IPI's research found that it was not possible to develop such a measurable tactic, so they instead presented guidelines, emphasizing three key needs:

1. optimizing tape storage;

2. facilitating the emergence of new automated tape transfer technology; and

3. the creation of a decision-making tool for implementing prioritized transfer programs. (Bigourdan 2006: 3)

This report added a new technological question to the video preservation discourse. It suggested that, in addition to paying attention to tape and playback deck sustainability, video preservationists must also place questions about migration strategies at the forefront. These were years when the obsolescence of analog video equipment was becoming more visible and optical media and digital media was growing more widespread, and the video preservation community remained concerned about the materiality of analog media. $^{7}$

\section{Collaboration and Change Management: Developments in Video Preservation Discourse, 2002-10}

The 2000s saw the rise of a new type of publication: the video preservation how-to. In 2002, Sherry Hocking, Luke Hones and Mona Jimenez wrote 'Reel to Real: A Case Study of BAVC's Remastering Model,"8 which documents specific technological steps for transferring tapes (based on the practices of the preservationists at BAVC) and uses language accessible to someone new to technology in the cultural heritage sector. The same year, AMIA published a set of Video Preservation Fact Sheets ${ }^{9}$ and Jim Wheeler documented best practices in a 'Videotape Preservation Handbook.'10 These how-to documents continued to articulate and develop strategies for contending with the materiality of videotape, but they also highlighted the importance of collaboration and what Star calls boundary-crossing-where new communities of practitioners (heritage professionals and independent media makers) draw on the expertise of an existing community of practitioners (technologists and engineers). In describing best practices and mechanisms for using analog decks in digital workflows, Hocking, Hones, and Jimenez rearticulated and reimagined what these machines could do. The intended uses of the machines are different than they were in the past, their work points out, because the user is different: although engineers may be hired to repair equipment, new figures are now also present as users-and thus, interpreters-of this machine technology and tape.

The early to mid-2000s also saw the emergence of other new conceptualizations of video preservation. In 'Developing Strategies for the Conservation of Installations Incorporating Time-based Media with Reference to Gary Hill's Between Cinema and a Hard Place' (2001), Pip Laurenson mapped out a distinct approach to video preservation, one that was not focused exclusively on the materiality of tape and playback equipment. Instead, she advocated for the development of an infrastructure that could account for continual change through documentation, consultation with artists, and adaptability. 'Conservation,' she wrote, 'is no longer focused on intervening to repair an art object' (Laurenson 2001: 260). It must also place, among its central concerns, 'documentation,' as well as consideration of 'what change is acceptable and [how to] manag[e] those changes' and the introduction of artists' voices into the preservation conversation (Laurenson 2001: 260). Soon thereafter, the Variable Media Initiative-a project maintained by the Guggenheim Museum-followed

\footnotetext{
${ }^{7}$ Manufacture of the last VHS compatible playback machine ceased in 2016; formats such as Umatic and 1/2" open-reel had by then been obsolete for some time.

${ }^{8}$ A study produced by Bay Area Video Coalition (BAVC), this report offers a practical walk-through of practices undergone during the preservation process by technicians at BAVC. Contemporaneously, this offers a consideration of past video preservation practice. http://www.experimentaltvcenter.org/reel-real-case-study.

${ }^{9}$ Association of Moving Image Archivists' Video Preservation Fact Sheets: https://amianet.org/wp-content/uploads/ResourcesVideo-Preservation-Fact-Sheets-2002-1.pdf.

${ }_{10}$ Video Preservation Handbook by Jim Wheeler: https://amianet.org/wp-content/uploads/Resources-Guide-Video-HandbookWheeler-2002.pdf.
} 
Laurenson's lead and began to create infrastructure designed to document an artwork's potential future rendering, inviting artists into the fold by pointedly asking technological questions designed to help future conservators recreate the work in as authentic a way as possible.

Laurenson and the Variable Media Project were building outward from previous considerations of video preservation, but they were also using process-based strategies to expand the grammar of this work. This new approach suggested that that audiovisual preservation ought to reconsider the presumption (to quote Lucy Suchman) that 'technical expertise is not only a necessary but is the sufficient, form of knowledge for the production of new technologies' (Suchman 2002: 93). In fact, the knowledge generously shared by engineers is necessary, but it is far from the only, or the sufficient, form of knowledge we need to maintain and shape the future of analog video preservation technologies. Laurenson's work also speaks to a larger project of grappling with the issue of change management and authenticity in electronic media-especially if we include migration between one format and another as a form of change management. ${ }^{11}$

At the same time, interest in the digitization of video grew. As a result, moving image archives took up new concerns about digital preservation (Fleischhauer 2003; Besser 2001). New projects, such as the National Digital Information Infrastructure and Preservation Program (NDIIPP), emerged to encourage 'collaboration among a wide range of partners' in developing digital preservation practices (Campbell 2002: 32). In these years, tape-to-tape transfer was still most commonly used to address concerns about authenticity and longterm viability. However, with the rise of new digital formats (and the increasing obsolescence of analog tape), digital preservation became a primary activity of the field. A marked shift in thinking was evident by 2012, when Karen Gracy asserted that 'digitization is no longer an emerging tool; it is the established and often preferred method for reformatting' (25). Since then, there has been a noticeable uptick in urgency in the conversation around analog video and magnetic media digitization, with many visible projects, such as the American Archive of Public Broadcasting project and Indiana University's Media Digitization and Preservation Initiative (MDPI), taking a bulk-digitization approach. ${ }^{12}$

\section{DIY and Experimentation: Recent Developments in Video Preservation Discourse}

The discourse of video preservation continues to develop in the texts of foundation-funded reports, scholarly writing, and conference papers. But in addition to these ways of sustaining and sharing knowledge, a lot of writing and knowledge production has begun to happen in shared and open-source platforms such as Github. ${ }^{13}$ Members of the moving image archiving community collaborate remotely through this and other platforms, sharing video preservation tips and strategies and documenting preservation and migrationoriented workflows with their peers. ${ }^{14}$

These forms of knowledge-sharing have opened up new kinds of conversations about video preservation that are hard to capture by way of a traditional literature review. Interviews with practitioners active in the field, however, offer a view into the new developments shaping video preservation discourse. A set of preliminary interviews I have conducted demonstrate that practitioners are noting a change in this conversation. For instance, Amy Sloper, Head Archivist at the Wisconsin Center for Film and Theater Research, observed that many preservationists have begun to address the limitations of sector-wide standards and practices, and in the process have adopted a more open approach to the work:

In the past five years, it seems like the conversation has shifted to people being honest about how they're actually doing stuff without feeling ashamed that they're not doing it perfectly. There's been an embracing of a 'just get it done' type attitude instead of feeling like you can't even get started because you don't have the right tools or knowledge ... an honesty about scales of practice has been really positive. (Sloper, interview by the author, February 19, 2018)

\footnotetext{
${ }^{11}$ Questions about authenticity in digital preservation were also central the InterPARES project, http://www.interpares.org/.

${ }^{12}$ American Archive of Public Broadcasting, http://americanarchive.org/; Indiana University Media Digitization \& Preservation Initiative, https://mdpi.iu.edu/.

${ }_{13}$ Mainly used for software development, Github has also been repurposed by the AMIA Open Source committee and by others as a place for documentation, resource-sharing and collaboration.

${ }^{14}$ See, for example, 'Amiaopensource/Open-Workflows: V2018-03-05,' Zenodo, Accessed March 5, 2018; 'Amiaopensource/TimeBased-Media-Art: Initial Release,' Zenodo, Accessed March 4, 2018, https://doi.org/10.5281/zenodo.1188869; and https://doi. org/10.5281/zenodo.1188373; 'Amiaopensource/Cable-Bible,' Zenodo, Accessed March 4, 2018. https://doi.org/10.5281/ zenodo.1188331.
} 
Sloper's comments suggest that this work is beginning to encompass new forms of infrastructure in a cultural heritage context wherein the process directly reflects the urgency of analog video preservation for these institutions. Operationalizing this urgency is the development of a community of shared and open knowledge bases, drawing from cooperative learning and collective input. John Klacsmann, Archivist at Anthology Film Archives, also noted the emergence of this more experimental and open approach. He observed that for his institution, finding equipment to repair damaged decks was not as great a barrier as one might think:

In the case of Umatic, ${ }^{15}$ we found some really good equipment, decks and unused parts from a production house that was closing ... It's a constant thing, we're always looking for old analog video equipment. A few months ago we bought a $1 / 2$ " open-reel video deck on eBay and it wasn't completely working. With a tiny bit of effort, I was able to replace some of the parts and get it running properly. (Klacsmann, interview by the author, February 21, 2018)

Dino Everett, archivist and curator at University of Southern California's Hugh M. Hefner Moving Image Archive, similarly referred to the recent rise in a do-it-yourself (DIY) ethic among video preservationists in my interview with him. As evidence, he cited collectively produced open-source software projects, and a willingness to perform in-house transfers, among other developments. In his view, this ethic has had a net positive effect on both the field, and his institution:

On a certain level there are smart people that are trying to share some of their knowledge. While I don't use it, BAVC came up with a [software] program as free and open source. Reto [Kromer] has worked on open source software, thinking 'you know what the whole field could benefit from this so I'm going to give it away.' We're all in the same general mission when there are opportunities to help each other I'm all for that, rather than how we can make money off of other people. (Everett, interview by the author, February 19, 2018)

Sloper also noticed that new, DIY-based approaches to video preservation have begun to reshape the discourse of video preservation. She pointed to the work of the XFR Collective, an all-volunteer group of archivists who use skill-sharing and mutual aid to maintain equipment and to reformat obsolete and at-risk video at a low cost for artists and activists, and its processor, XFR STN.$^{16}$ Indeed, XFR STN-a public digitization project put on by the New Museum in New York City-operationalized the idea of 'infrastructure in process of transformation' and opened up video preservation as a process visible to those outside a cultural heritage setting $^{17}$ (Sloper, interview by the author, February 19, 2018).

These ideas are not new, but they are gaining a new relevance within the visible discourse of video preservation. For some time before analog video preservation became, by necessity, synonymous with digitization and the digital preservation of resulting files, the preservation practices developed by media conservators and audiovisual archivists included sharing resources, experimentation, and working with experts in obsolete technology and infrastructure. Over the years, more and more research activity has helped improve and develop practices based on multiple viewpoints rather than a singular, overarching 'best practice,' suggesting that technological developments and the resources available to implement them often offer more complex but doable arrangements and scope for community work than it may seem when these technologies are first praised using the perhaps superficial rhetoric that surrounds innovation.

\section{Conclusion}

Analog video preservation advocacy and development has arrived at its current state because it has concentrated on recovering a dying analog video production infrastructure. Responding to proprietary equipment obsolescence and the difficulties of finding and using aging equipment that is often in need of repair, video preservationists have developed a maintenance regime as the focal point of preservation. The infrastructure supporting this discursive regime includes networks of archivists, museum conservators,

\footnotetext{
15 3/4" Umatic is an analog videotape format manufactured from the late 1960s into the 1990s. It was a popular format for independent media-makers to master to from source material for editing purposes. It is at a high risk for sticky-shed syndrome, and videotape decks to playback tapes for digitization and preservation purposes have been obsolete for many years.

${ }^{16}$ XFR Collective, a media digitization initiative and non-profit based in New York City, with an off-shoot in Boston, Massachusetts. https://xfrcollective.wordpress.com/.

17 'The New Museum dedicated its Fifth Floor gallery space to "XFR STN" (Transfer Station), an open-door artist-centered media archiving project.' https://www.newmuseum.org/exhibitions/view/xfr-stn.
} 
video engineers-all of whom have their own areas of expert knowledge and their ideas about the material component parts of video preservation equipment.

There is no question that the materiality of tape and playback equipment is critically important to consider when devising strategies to conserve and preserve content that was originally recorded on analog video. The efforts taken on by the analog video preservation practitioner community to develop standards and engage in advocacy over several decades have been no small feat. Due to these efforts, there exists an infrastructure of knowledge, systems, documents, equipment, projects, and practices that support archivists' efforts to translate analog video production materials and practices into a new digital context. Chief among these infrastructures is a system of tools that support the operationalization of analog playback decks, cables, and interfaces within a digital/digitization workflow.

But I wish to suggest that the laser focus with which video preservationists have focused on 'things' rather than 'processes' (to refer back to Star and Bateson's ideas, as described above) over the years may need some reconsideration. Invisible labor has supported technology in archives and contributed to the interchange of knowledge practices from one era to the next, and one field to another. How might a focus on labor that produces processes and infrastructure shifts be captured within the discourse of preservation scholarship? What would happen if we moved some attention to places of boundary-crossing and maintenance that are simultaneously dense and dynamic webs of knowledge? Can we locate the infrastructures of knowledge that have shaped this work and use this knowledge to denaturalize the claims that are made around that knowledge?

A direct level of inquiry like the one Star outlines in 'Ethnography of Infrastructure' is a future direction to expand on this research. Future research could entail participant observation conducted on-site with machinery and manuals, documenting the working by thinking, thinking by working that can occur when infrastructure or workplace habits become seen by the person pursuing them as commonplace or unworthy of study. This approach can offer an opportunity to decipher and examine the intricate articulation work that is pursued by maintainers of the infrastructure, furthering our understanding of the sociotechnical and archival labor implications of technological manufacture, production, and maintenance. If this essay does anything besides engaging in a conversation about the history of analog video preservation, hopefully it will serve as encouragement for academics and practitioners to more closely collaborate. The symbiosis between creation and preservation is very apparent in tracing the history of video preservation within cultural heritage practice, and archivists and scholars may wish to work together to promote the study of the everyday and seemingly insignificant labor practices in the service of furthering what archives do best: holding those in power to account, and maintaining the material of history.

\section{Ethics and Consent}

The author was granted Institutional Review Board approval by North General IRB at the University of California, Los Angeles, and obtained signed informed consent forms from all participants. Reference number is: IRB\#18-000147.

\section{Acknowledgements}

Sincere thanks to Dr. Rachel Mattson for her considerable and generous contributions to the editorial and intellectual structure of this piece. Thanks also to my advisor, Dr. Anne Gilliland, for her notes and edits, my mentor Mona Jimenez for her inspiring work in the area of analog video preservation, and all my friends and family for their support.

\section{Competing Interests}

The author has no competing interests to declare.

\section{References}

Arnold, Hillel. 2016. "Critical Work: Archivists as Maintainers." Hillel Arnold (blog), August 2, 2016. https:// hillelarnold.com/blog/2016/08/critical-work/. Archived at: https://perma.cc/P3L7-GS2M.

Bateson, Gregory. 1987. Steps to an Ecology of Mind. 2nd ed. Northvale, NJ and London: Jason Aronson Inc. Besser, Howard. 2001. "Digital Preservation of Moving Image Material?" The Moving Image: The Journal of the Association of Moving Image Archivists, 1(2): 39-55. https://www.jstor.org/ stable/41167061.

Bigourdan, J., James M. Reilly, Karen Santoro, and Gene Salesin. 2006. "The Preservation of Magnetic Tape Collections: A Perspective." NEH Grants PA-50123-03. Rochester, NY: Image Permanence Institute, Rochester Institute of Technology. 
Boyle, Deirdre. 1993. Video Preservation: Securing the Future of the Past. New York, NY: Media Alliance; New York, NY: New York State Council on the Arts. https://archive.org/details/videopreservatio00boyl.

Campbell, Laura. 2002. "The National Digital Information Infrastructure and Preservation Program (NDIIPP) and Its Implications for a Research Agenda for Digital Preservation." Library and Information Research, 26(84): 32-40. https://www.lirgjournal.org.uk/index.php/lir/article/view/140.

Cuddihy, E. 1980. "Aging of Magnetic Recording Tape." IEEE Transactions on Magnetics, 16(4): 558-68. DOI: https://doi.org/10.1109/TMAG.1980.1060652

Everett, Dino. 2018. Interview by Lauren Sorensen, February 19, 2018.

Fleischhauer, Carl. 2003. "Looking at Preservation from the Digital Library Perspective." The Moving Image: The Journal of the Association of Moving Image Archivists, 3(2): 96-100. DOI: https://doi.org/10.1353/ mov.2003.0027

Gracy, Karen F., and Miriam B. Kahn. 2012. "Preservation in the Digital Age." Library Resources \& Technical Services, 56(1): 25. DOI: https://doi.org/10.5860/lrts.56n1.25

International Standards Organization (ISO). 2012. Imaging Materials - Magnetic Tape - Care and Handling Practices for Extended Usage. ISO 18933: 2012. Geneva, Switzerland: ISO.

Kalil, Ford. 1982. Magnetic Tape Recording for the Eighties. Washington, DC: NASA. https://ntrs.nasa.gov/ search.jsp?R=19820021703.

Klacsmann, John. 2018. Interview by Lauren Sorensen, February 21, 2018.

Laurenson, Pip. 2001. "Developing Strategies for the Conservation of Installations Incorporating Time-Based Media with Reference to Gary Hill's Between Cinema and a Hard Place." Journal of the American Institute for Conservation, 40(3): 259-66. DOI: https://doi.org/10.1179/019713601806113003

Sargent, Ralph. 1974. Preserving the Moving Image. Washington, DC: The Corporation for Public Broadcasting; Washington, DC: National Endowment for the Arts.

Sloper, Amy. 2018. Interview by Lauren Sorensen, February 19, 2018.

Star, Susan Leigh. 1999. "The Ethnography of Infrastructure." American Behavioral Scientist, 43(3): 377-91. DOI: https://doi.org/10.1177/00027649921955326

Suchman, Lucy. 2002. "Located Accountabilities in Technology Production." Scandinavian Journal of Information Systems, 14(2): 7.

Van Bogart, J. W. C. 1995. "Magnetic Tape Storage and Handling: A Guide for Libraries and Archives." Washington, DC: Commission on Preservation and Access; St. Paul, MN: National Media Laboratory.

Welz, Gerhard. 1987. "On the Problem of Storing Videotapes." In: Archiving the Audiovisual Heritage. West Berlin, Germany: Coordinating Council of Audiovisual Archiving Associations. https://www.fiafnet.org/ images/tinyUpload/Events/Other-Events/Berlin-1987-RED.pdf. Archived at: https://perma.cc/H7TG$7 \mathrm{MLE}$.

Wheeler, Jim. 1983. "Long-term Storage of Videotape." In: Archiving of the Moving Image in the 21st Century. Stockholm, Sweden: Coordinating Council of Audiovisual Archiving Associations. https://www.fiafnet. org/images/tinyUpload/Events/Other-Events/Stockholm\%201983-RED.pdf. Archived at: https:// perma.cc/WFH6-QRKZ.

Wheeler, Jim. 1987. "Archiving the Various Audio and Video Format." In: Archiving the Audiovisual Heritage. West Berlin, Germany: Coordinating Council of Audiovisual Archiving Associations. https://www.fiafnet. org/images/tinyUpload/Events/Other-Events/Berlin-1987-RED.pdf. Archived at: https://perma.cc/ H7TG-7MLE.

How to cite this article: Sorensen, Lauren. 2018. Analog Video in Moving Image Archives \& Conservation: Infrastructures of Knowledge from Production to Preservation. KULA: knowledge creation, dissemination, and preservation studies 2(1): 8. DOl: https://doi.org/10.5334/kula.32

Submitted: 12 March $2018 \quad$ Accepted: 17 October $2018 \quad$ Published: 29 November 2018

Copyright: (c) 2018 The Author(s). This is an open-access article distributed under the terms of the Creative Commons Attribution 4.0 International License (CC-BY 4.0), which permits unrestricted use, distribution, and reproduction in any medium, provided the original author and source are credited. See http://creativecommons.org/ licenses/by/4.0/.

$\mid \mathrm{u}[\quad$ KULA: knowledge creation, dissemination, and preservation studies is a peer-reviewed open access journal published by Ubiquity Press. 